\title{
Investigation of vibration modes of a double-lap bonded joint
}

\author{
Amal Zeaiter ${ }^{1}(\mathbb{D}) \cdot$ Georges Challita $^{1} \cdot$ Khaled Khalil $^{1,2}$ \\ (c) Springer Nature Switzerland AG 2019
}

\begin{abstract}
The authors were concerned in this work in examining the influence of many mechanical and geometrical parameters on the mode shapes of vibration of a double-lap bonded joint. The parameters varied in this study were: adhesive Young's modulus, adhesive and adherents' thicknesses and overlap length. The substrates were made from steel; the adhesive is an epoxy resin. The study was carried out using ANSYS Finite Element software where the first ten modes were extracted. The results obtained from an experimental test conducted by the same workgroup were used to validate the numerical results. Based on the numerical parametric study, the results have shown a dominant influence of the substrates' thickness and the overlap length: the natural frequency increases remarkably with those two parameters. Moreover, the frequencies of the first ten modes were found to be very sensitive in increasing with the increment of either the adherents' thicknesses or the overlap length. On the other hand, the influence of the adhesive Young's modulus was found to be very slight on increasing the natural frequencies for all modes while the adhesive thickness was found to have quite no influence for the first couple of modes, with a slight decrement of frequency for higher modes. Finally, by setting the latter parameters to reference values, a unified parameter function of overlap length and adherent thickness was defined and approximated, and analytical relations for natural frequencies of the first ten modes were established.
\end{abstract}

Keywords Modal analysis · Adhesive · Double-lap joint · Finite element

\section{List of symbols}

$a \quad$ Overlap length (mm)

$L \quad$ Length of plates $(\mathrm{mm})$

$E \quad$ Adhesive Young's modulus (GPa)

$t_{a} \quad$ Adhesive thickness $(\mathrm{mm})$

$t_{c} \quad$ Central plate's thickness (mm)

$t_{e} \quad$ Exterior plates' thickness (mm)

$W \quad$ Structure width (mm)

$\omega \quad$ Natural frequency of the structure $(\mathrm{Hz})$

\section{Introduction}

Adhesive bonding is a joining technique that is becoming widespread in the world of industry. Actually, it offers many advantages over traditional means of assembling such as bolting, riveting or welding. Structures are light; assemblies' preparation is simple and time-saving and stresses are distributed on a large surface of contact. Such assemblies have many applications especially in automotive engineering and aeronautics where they are permanently subjected to many types of loading, one of them is vibration. This explains the interest of many engineers and researchers to study those structures under vibration and this is where the current work is useful for application.

Saito and Tani [1] established an analytical model to study the natural frequencies and the loss factor of single-lap joint beams under coupled axial and bending vibration. Khalil and Kagho [2] developed a non-destructive vibrational approach to detect defects, such as voids and disjoints, in a single lap joint through resonant frequencies' measurements. The analytical governing equations of single lap jointed beams with viscoelastic adhesive under transverse and longitudinal vibration constituted the main concern of $\mathrm{He}$ and Rao [3].

\footnotetext{
$\triangle$ Amal Zeaiter, zeaiteramal@gmail.com; Georges Challita, georges.challita@ul.edu.lb; Khaled Khalil, khkhali@@ul.edu.lb| ${ }^{1}$ MMC Group-CRSI, Faculty of Engineering, Lebanese University, Hadath Campus, Beirut, Lebanon. ${ }^{2} \mathrm{EMM}-\mathrm{GeM}$, Research Institute of Civil and Mechanical Engineering UMR CNRS 6183, IUT of Saint-Nazaire, 58 Street Michel Ange, BP 420, 44606 Saint-Nazaire, France.
}

SN Applied Sciences (2019) 1:466 | https://doi.org/10.1007/s42452-019-0340-8 
They presented in [4] the numerical solution of their model. A similar job was done by Rao and Zhou [5] on tubular joints; they investigated, in addition, the effect of structural parameters and material properties of the adhesive on the modal loss factor and the resonant frequencies. Numerically, Ko et al. [6] have established a finite element formulation based on isoparametric adhesive interface element where responses of each substrate and the adhesive layer were found separately. Later on, Lin and Ko [7] extended the latter analysis and applied it to a cantilevered stepped bonded plate. Yeh and You [8] have studied experimentally and analytically single-stepped lap composite laminated joints in order to extract the fundamental frequency. They examined the effect of adhesive thickness and fibers orientations. A 3D FEM technique through ABAQUS was applied by $\mathrm{He}$ and Oyadiji [9] on a cantilevered single lap adhesively jointed beams where the effect of Young's modulus and Poisson's ratio of the adhesive on the natural frequencies and mode shapes of transverse vibration were investigated; in addition they studied the effect of the adhesive strength. Vaziri et al. [10] evaluated analytically the dynamic response of single lap bonded joint subjected to out-of-plane harmonic force; they found that the system is less sensitive to a certain margin of adhesive loss factor and also to the void's size in the adhesive layer while the location of this void had a remarkable influence. Shear and peel stresses in the overlap region were also obtained. In the same context, Vaziri and Nayeb-Hashemi [11] repeated almost a similar study but for tubular joint under an axial dynamic load; they investigated also properties and geometries for the elastic substrates and viscoelastic adhesive. The same authors studied in [12] theoretically and experimentally the dynamic response of a composite adhesively-repaired beam under harmonic peel loading, a FEM validation was also carried out. Gunes et al. [13] investigated, using two numerical approaches: finite elements and artificial neural network, the effect of geometrical parameters on the free vibration of functionally graded single lap joint. They found also that the first ten modes were insensitive to Young's modulus, Poisson's ratio and density of the substrates. An optimal sizing of the joint was also developed. In [14], they carried out similar study but for substrates composed of ceramic $\left(\mathrm{Al}_{2} \mathrm{O}_{3}\right)$ and metal (Ni) varying them through the thickness. Torsional vibration study of single lap joints was the main concern of $\mathrm{He}$ [15] using both numerical and experimental approaches: he found that the natural frequencies increase with Young's modulus of the adhesive and are insensitive to the Poisson's ratio. The stiffness of the adhesive has a huge influence on the torsional mode shapes. Garcia-Baruetabeña and Cortés [16] developed an experimental procedure to study the influence of geometrical parameters of a bonded metallic beam on its vibrating behavior. They determined resonant frequencies, amplitudes and loss factors. The relationship between vibration and fatigue was tackled by Du and Shi [17] using steel-aluminum single lap joint: they found that when vibration fatigue cycles increase the modal frequencies decrease. They investigated numerically the effect of adhesive Young's modulus and the contact area of bonding. Samaratunga et al. [18] developed an analytical model called wave spectral finite element to examine the wave propagation in a single lap adhesively composite beam; this model was numerically validated by a finite element method through ABAQUS. However, one can easily remark that most of the works carried out in vibration study have already used the single lap geometry (SLJ) as a default specimen; the double-lap geometry (DLJ) was rarely investigated under such phenomenon. Nevertheless, this latter geometry offers a remarkable advantage over SLJ by exhibiting two planes of symmetry which lead to avoid coupling between axial and bending modes. Maybe the analytical model developed by Challita and Othman [19] is one of the rare works where the shear response was determined for a DLJ subjected to harmonic axial loading using the improved shear lag model. This geometry was studied under impact but not under vibration. In [20], the influence of some adherents' properties on natural vibration of a double-lap joint was examined. One can cite many numerical works carried out in this field [21-25] and experimental works [26, 27]. In those works, both metallic and composite substrates were considered. In this paper, a parametric numerical finite element study will be carried out on ANSYS to investigate the natural frequencies $(\omega)$ and mode shapes of a DLJ structure made of steel as substrates and an epoxy resin as adhesive. Impulse Excitation Technique (IET) was used to measure experimentally the natural frequencies of DLJ specimens; it has shown good agreement with numerical simulations with a maximum error of $8 \%$. The parameters to be examined are mechanical: the adhesive Young's modulus, and geometrical: the adhesive thickness, the adherent thickness, and the overlap length. The study is carried out systematically such that only one parameter changes while all the others are set to reference values. This will allow investigating the effect of each parameter independently from the others and finally, a unified parameter involving all the studied parameters was established; it is useful to estimate the natural frequencies upon a defined configuration of the DL. In other words, this parameter could be helpful for design purposes.

\section{Numerical model}

\subsection{Specimen description}

The structure in this study, which is the double-lap adhesive joint, consists of three rectangular plates bonded together. The central plate is shifted horizontally with respect to the 


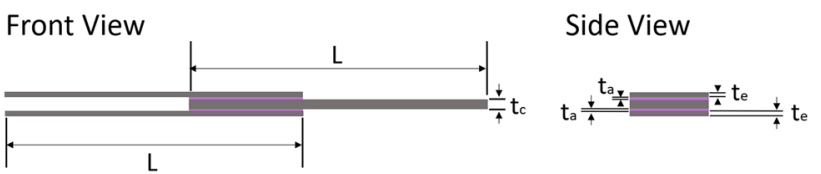

Top View

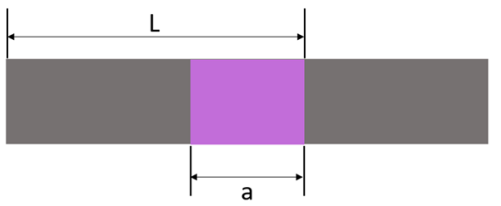

Fig. 1 Reference model of the structure

extreme ones. Those latter are cantilevered at one end; the other end of the central plate is free. Exterior plates have always half of the thickness of the central one, and all plates are $10 \mathrm{~cm}$ long. The DLJ reference model is presented in Fig. 1 and its geometrical properties used in the simulation part are summarized in Table 1. The plates are made from steel more specifically Steel S-7 while the adhesive is Epoxy resin. Mechanical properties of these two materials for the reference model of the simulations are grouped in Table 2. The parameters to be examined are: adhesive Young's modulus ' $\mathrm{E}$ ', adhesive thickness ' $\mathrm{t}_{\mathrm{a}}$ ', thickness of central plates ' $\mathrm{t}_{\mathrm{c}}$ ' and overlap length 'a'. It should be noticed that the reference value of 'a' was chosen to be $30 \mathrm{~mm}$ in order to define a percentage of coverage with respect to the total length of the adherent $(100 \mathrm{~mm})$ and hence an overlap ratio of $30 \%$ was set. This ratio is an indicator of the overall stiffness of the assembly. In addition, the choice of $0.2 \mathrm{~mm}$ for the adhesive thickness was found to be a compromise between much lower values which might create very high peaks of stresses at the edges and lead to crack appearance during vibration and much higher values which weaken the resistance and imply a drop in the overall stiffness of the structure.

\subsection{Finite element model}

To proceed with the numerical simulation of the double-lap joint structure on ANSYS, the module ANSYS-Modal is used to elaborate and simulate the FE model. The contact region between the plates and the adhesive is of bonded type, set
Table 2 Materials' characteristics for the simulation reference model

\begin{tabular}{lll}
\hline Characteristics & Materials & \\
\cline { 2 - 3 } & Steel & Epoxy resin \\
\hline Young's modulus (GPa) & 205 & 3 \\
Poisson's ratio & 0.29 & 0.33 \\
Density $\left(\mathrm{kg} / \mathrm{m}^{3}\right)$ & 7750 & 1186 \\
Shear modulus $(\mathrm{GPa})$ & 79.5 & 11.3 \\
\hline
\end{tabular}

Table 3 Converging study for mesh size

\begin{tabular}{lllll}
\hline Element size (mm) & 0.036125 & 0.06125 & 0.125 & 0.25 \\
$\begin{array}{c}\text { Simulation time (min) } \\
\text { Min \% of time-saving }\end{array}$ & 30 & 23 & 20 & 17 \\
$\begin{array}{c}\text { with respect to maxi- } \\
\text { mum mesh size }\end{array}$ & & $35 \%$ & $18 \%$ & N/A \\
$\begin{array}{c}\text { Max \% of frequency dif- } \\
\text { ference with respect to } \\
\text { maximum mesh size }\end{array}$ & $0.1 \%$ & $0.02 \%$ & $0.0 \%$ & N/A \\
\hline
\end{tabular}

in Connections. For the mesh sizing of the model, it is set accurately after a convergence study presented in Table 3. It is remarkable that when adopting the max mesh size $(0.25 \mathrm{~mm})$ compared to min mesh size $(0.036125 \mathrm{~mm})$ there is a relatively high percentage of time-saving (77\%) and an insignificant difference in frequency (0.1\%). Different simulation trials contributed into the elaboration of the best mesh size, which is $0.25 \mathrm{~mm}$; above this value, the mesh is large and the compromise Time-Accuracy is exceeded since the thickness of the adhesive layer is not covered by more than one full element. Other meshing details are specified for correspondence with the specimen geometry: the Element Quality is chosen for the Mesh Metric, for the mesh type, Hexahedra have the highest accuracy among all types and are suitable to use especially for the 3D meshing bonded plates orthogonally structured. $0.25 \mathrm{~mm}$ minimum element size FEM model of the assembly is displayed in Fig. 2. Finally, one should notice that the mesh refinement at the edges of the joint was not necessary since the study does not concern stress or fracture analysis; the study is simply a modal analysis.

Table 1 Dimensions of the simulation reference model

\begin{tabular}{|c|c|c|c|c|c|c|}
\hline Parameters & $\begin{array}{l}\text { Thickness of exte- } \\
\text { rior plates } t_{e}\end{array}$ & $\begin{array}{l}\text { Thickness of central } \\
\text { plate } t_{c}\end{array}$ & $\begin{array}{l}\text { Length of each of } \\
\text { the } 3 \text { plates } L\end{array}$ & Overlap length a & $\begin{array}{l}\text { Adhesive thick- } \\
\text { ness } t_{a}\end{array}$ & Plate width W \\
\hline Dimensions (mm) & 2 & 4 & 100 & 30 & 0.5 & 30 \\
\hline
\end{tabular}




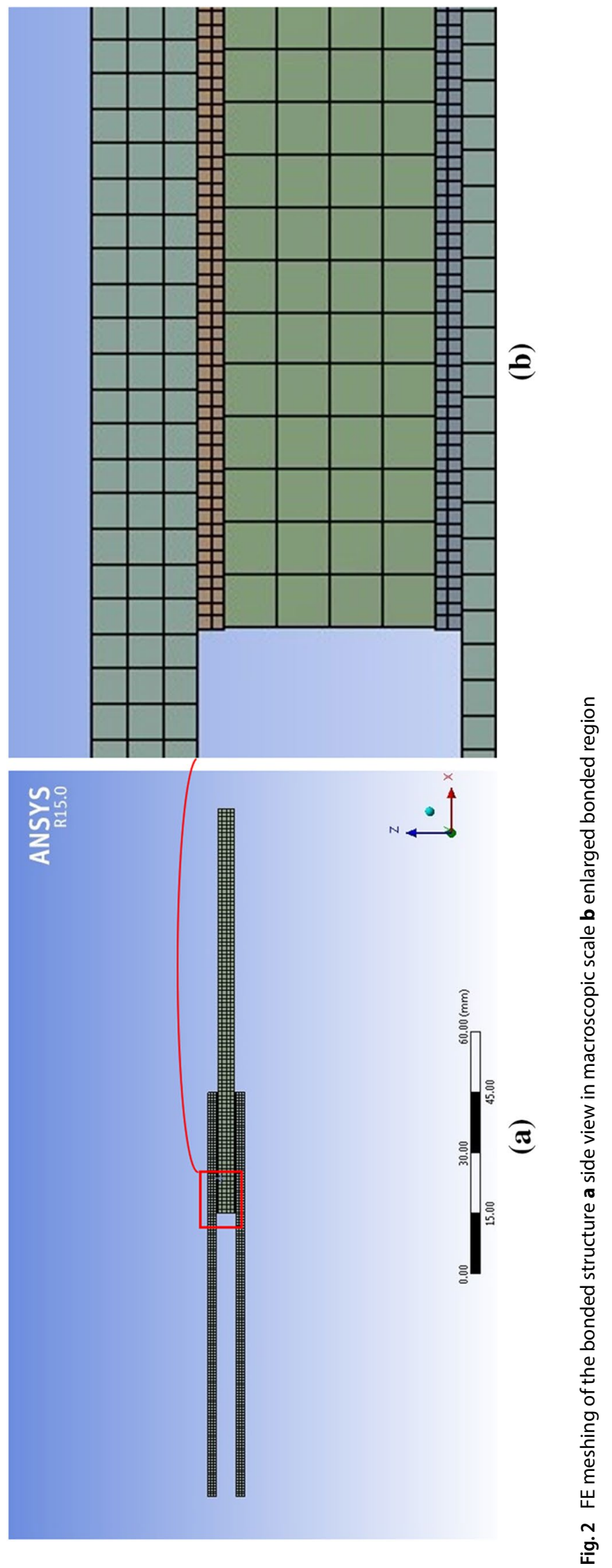


Fig. 3 Model windows on ANSYS showing solution of the first mode shape

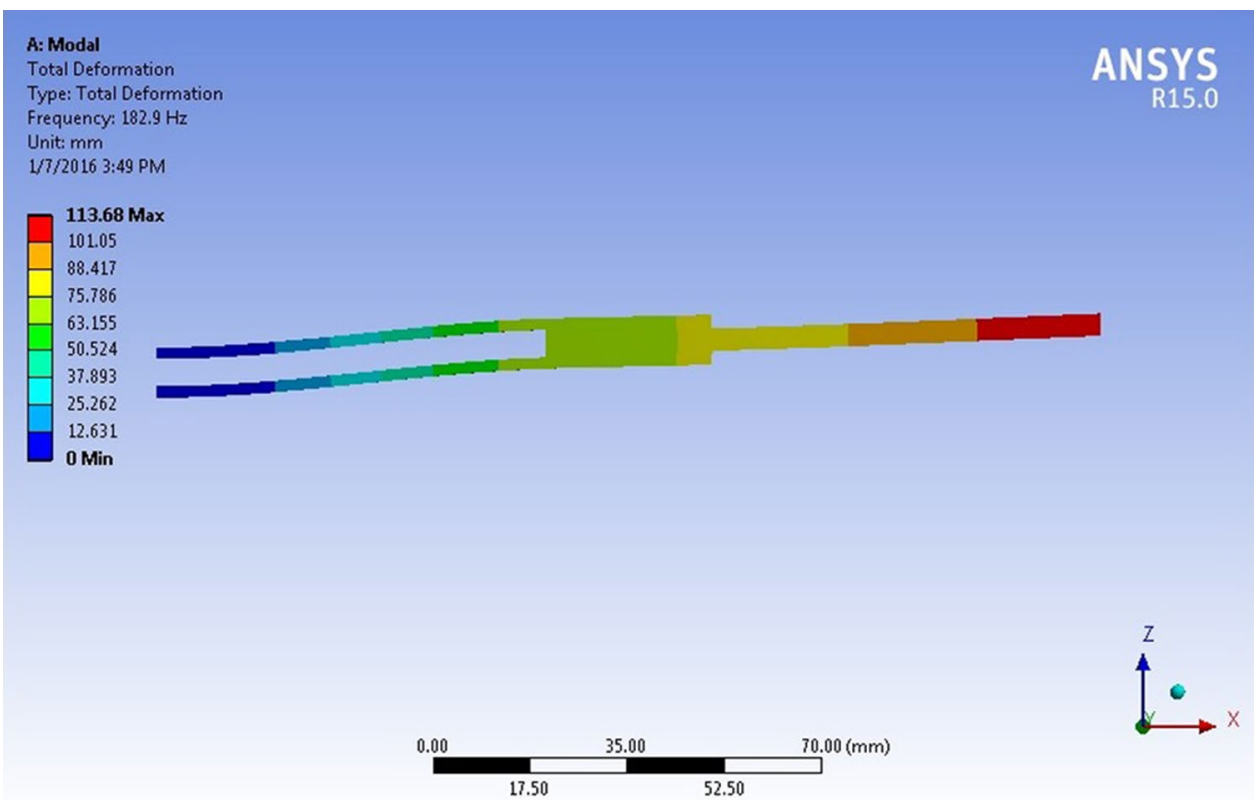

\section{Experimental validation}

Bonded assemblies are influenced by a huge number of parameters. To establish a criterion, it is worth as a first step to examine the effect of each parameter separately on the vibrating behavior. This was performed in the present work in order to understand deeply the influence of each parameter and later establish a unified parameter taking into consideration all the analyzed parameters together.

The reference model is a set of geometrical and mechanical characteristics of the specimen. This model will be the base of the parametric study: only one value for one parameter per simulation will be changed, all the other values will remain as set in the reference model (Tables 1 and 2). This avoids getting coupling effects.

In ANSYS, this model is simulated in modal analysis mode then the first mode shape appears as presented in ANSYS window of Fig. 3 and evaluated to get the solutions for all modes as shown in Fig. 4. Corresponding frequencies for each of the ten mode shapes are grouped in Table 4.

The effect of parameters' variation is examined in this work according to Table 5. Each parameter is studied separately from the others whose values remain constant as in the reference model.

In fact, a group of practical values for each parameter was chosen in Table 5. However, it was also gone beyond those values by adding some theoretical values to stay on the safe side in covering a wider range of values; this does not mean that all the below mentioned values are applied in practice.
For the specimen preparation and the bonding technique as shown in Fig. $5 a$, b, the steel plates were deburred using glass paper, then cleaned using ethanol. A special mounting base plate was used to prepare 5 specimens simultaneously. This plate is drilled to fix all the substrates in their corresponding positions. Studs were used to prevent motion of the substrates in the axial direction. The adhesive was spread on the surface of the adherents using a spatula. A common pressure plate is applied on the 5 specimens and bolted to the main plate of the mounting on the bonded specimens. The fasteners and the pressure plate prevent the motion of the assembly in the lateral direction and the orthogonal direction to the base plate. Before application, a special product was applied on all the fixing components to avoid any adhesion once the epoxy overflows after the pressure is applied. Spacers were used to ensure the alignment of the substrates. The cure time at the ambient temperature was about 1 week to make sure that the polymerization was completed. The IET $[28,29]$ and the RFDA professional signal analysis system (Resonance Frequency and Damping Analysis) from IMCE Company (Genk, Belgium) were used to execute the experimental part. The same research group, collaborating with the University of Troyes [30], conducted this part. The first technique allows the determination of Young's moduli, while the RFDA allows finding the vibrational modes of the structure. It is based on exciting the specimen and observing its natural frequencies. The test bench consists device to compress the joint and apply uniform pressure 

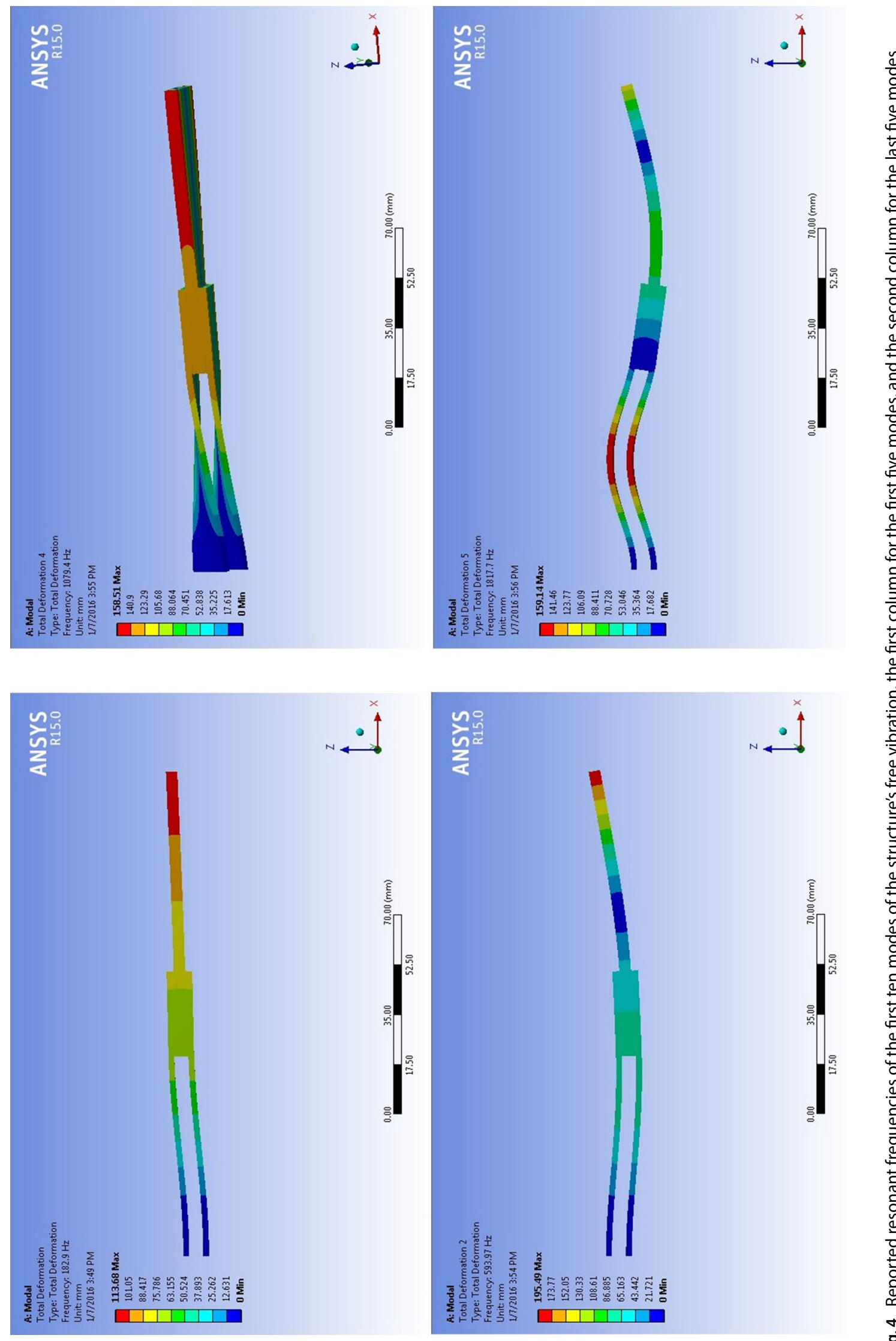

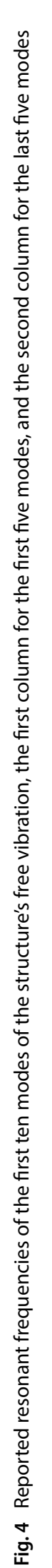



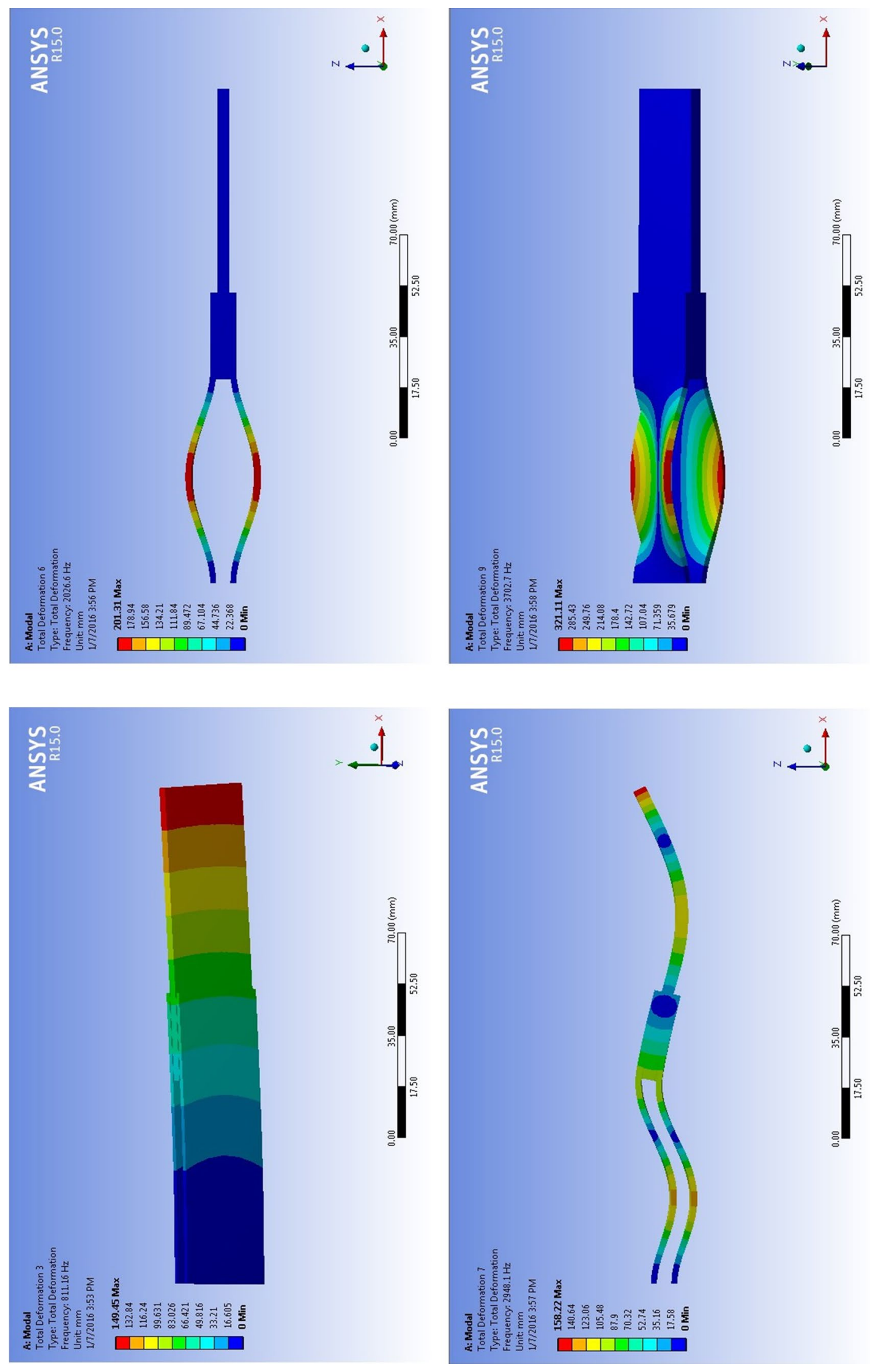

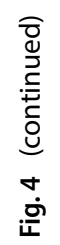




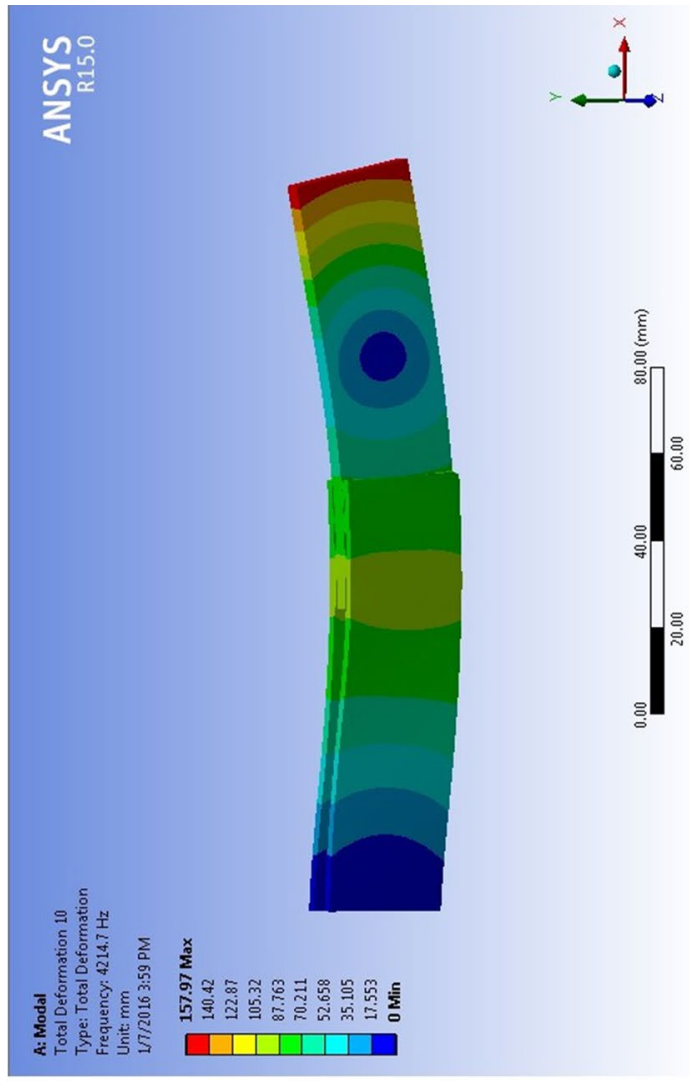

Table 4 Reported natural frequency of the structure for the first ten mode shapes

\begin{tabular}{ll}
\hline Modes & $\begin{array}{l}\text { Reported } \\
\text { frequency } \\
(\mathrm{Hz})\end{array}$ \\
\hline Mode 1 & 182.9 \\
Mode 2 & 593.97 \\
Mode 3 & 811.16 \\
Mode 4 & 1079.5 \\
Mode 5 & 1817.8 \\
Mode 6 & 2026.7 \\
Mode 7 & 2948.2 \\
Mode 8 & 3307.7 \\
Mode 9 & 3702.8 \\
Mode 10 & 4214.9 \\
\hline
\end{tabular}

of an RFDA transducer, a microphone, an excitation tool, the support and the RFDA software installed in a computer (Fig. 6). A sample specimen from the current study was tested (Fig. 7) having the characteristics reported in Table 6 which are real values of the parameters included in the numerical study. The target is to validate numerically the experimental work. Once validated, one might use numerically another set of values for the parametric study (Tables 1 and 2). Figure 8 shows the comparison between experimental and numerical results of this specimen. The obtained relative error between experimental and numerical results ranges from 0.8 to $8 \%$. It can be considered then, that the simulation's results agreed well with the experimental ones and that they can represent the real behavior of the model under vibration analysis. This agreement allows conducting numerically the parametric investigation, as result, will save enormously time and costs of the experimental investigation.

\section{Parametric study}

\subsection{Adhesive Young's modulus}

The effect of the adhesive Young's Modulus on free vibration of the structure has been studied by changing its value from 0.5 up to $10 \mathrm{GPa}$. While in the experimental study, the Young's modulus of the adhesive used is $0.5 \mathrm{GPa}$ and hence classified as soft, in the parametric study, and to be on the safe side of values coverage, a wider range of Young's modulus values was considered to cover the practical range with some theoretical values (like $7 \mathrm{GPa}$ and $10 \mathrm{GPa}$ ). Even though, this highest theoretical value remains far from the substrates'Young's modulus which helps in minimizing the edge effect at the joint during vibrating motion. The evolution of the natural frequency for each mode is depicted in the graphs of Fig. 9a, b. A negligible increase in frequency 
is observed for all modes and all variations. But it is crucial to note that the structure exhibits the highest slope in frequency increase reaching $10 \%$ for modes 4 and 10 , while for other variations, this increase rarely exceeds $1 \%$. Globally, increasing the adhesive's Young's modulus will lead to an increment of the overall stiffness of the structure, but since the adhesive stiffness is low with respect to substrates' ones, the stiffness increment is slight and thus the increase of the natural frequencies for modes is also slight. Figure 10 shows the variation of natural frequency as function of increasing modes, where each isocurve corresponds to a specific value of Young's modulus. Resulting curves significantly indicate the negligible effect of the adhesive Young's modulus.

\subsection{Adhesive thickness}

The effect of the adhesive thickness on the free vibration of the structure is investigated by changing its value from 0.2 up to $1 \mathrm{~mm}$. Results of the mode shapes and natural frequencies are presented in Fig. 11a, b. For the first 7 modes, no remarkable change in frequency is concluded. One can remark from this graph the inverse relation between the adhesive thickness and the natural frequency for the last three modes of vibration. Indeed, increasing adhesive thickness implies a decrease in the structure's stiffness and a slight increase in mass, since the layer is thin, this stiffness decrease is slight and thus a slight decrease of natural frequencies was detected at high modes. In spite of the inverse

Table 5 Parametric study's variations

\begin{tabular}{llllllll}
\hline Parameter & \multicolumn{7}{l}{ Variation } \\
\hline Adhesive Young's modulus (GPa) & 0.5 & 1 & 2 & 3 & 5 & 7 & 10 \\
Adhesive thickness (mm) & 0.2 & 0.3 & 0.5 & 0.6 & 0.8 & 1 & \\
Central adherent thickness (mm) & 2 & 3 & 4 & 5 & 6 & 7 & 8 \\
Overlap length (cm) & 1 & 2 & 3 & 5 & 6 & 8 & \\
\hline
\end{tabular}

\section{Top view}

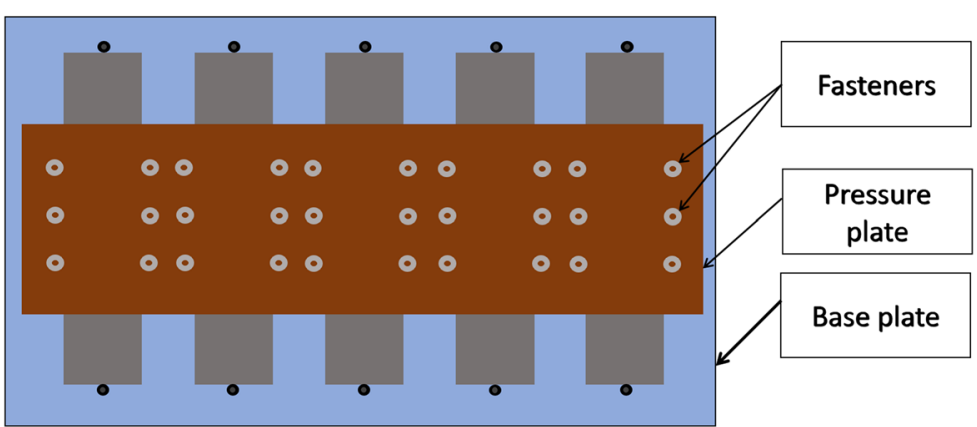

(a)

\section{Side view}

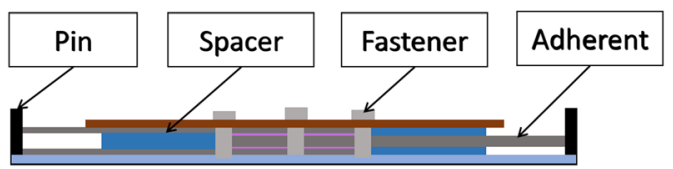

(b)

Fig. 5 Specimens' preparation for experimental bench

Fig. 6 Experimental setup for natural frequency determination using RFDA [30]

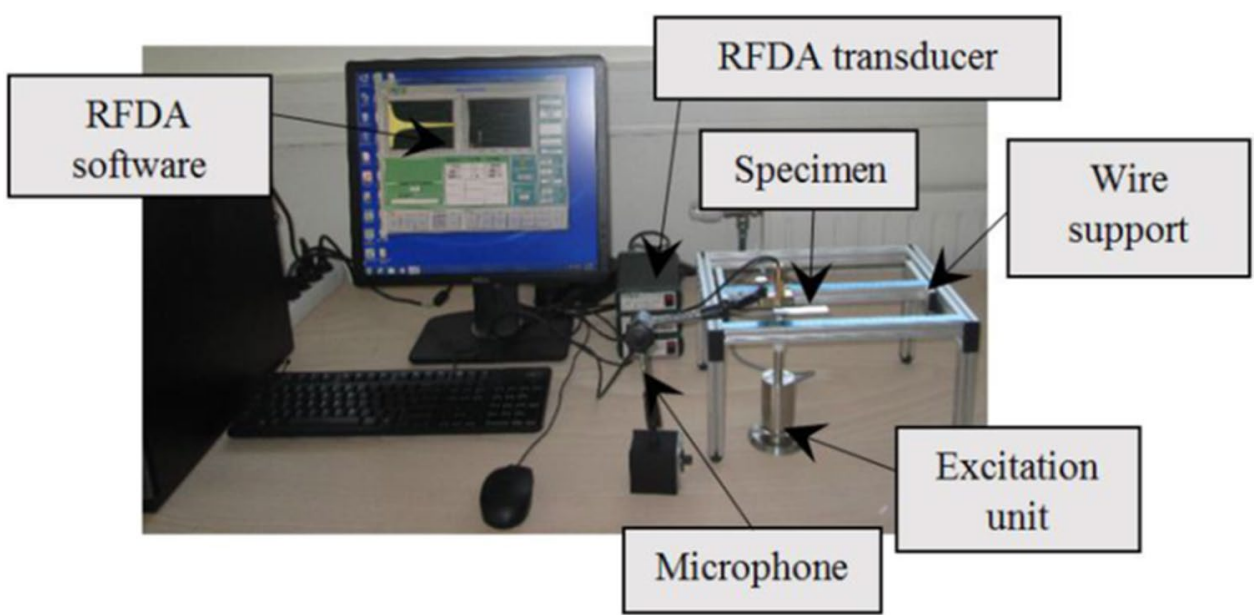

SN Applied Sciences A SPRINGER NATURE journal 
Fig. 7 Steel specimen prepared for experimental testing [30]

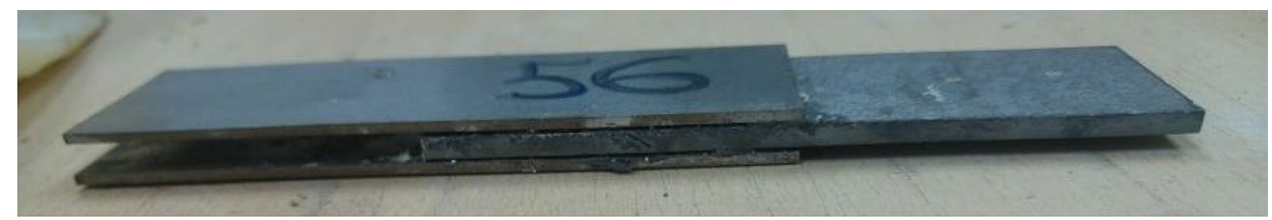

Table 6 Characteristics of the specimen model tested

\begin{tabular}{lllll}
\hline $\begin{array}{l}\text { Specimen } \\
\text { character- } \\
\text { istics }\end{array}$ & $\begin{array}{l}\text { Young's mod- } \\
\text { ulus (MPa) } \\
\text { adherent }\end{array}$ & $\begin{array}{l}\text { Poisson's } \\
\text { ratio }\end{array}$ & $\begin{array}{l}\text { Density }(\mathrm{kg} / \\
\left.\mathrm{m}^{3}\right)\end{array}$ & $\mathrm{t}_{\mathrm{a}}(\mathrm{mm})$ \\
\hline Adherent & 200,000 & 0.3 & 7850 & 0.3 \\
Adhesive & 500 & 0.35 & 1595 & \\
\hline
\end{tabular}

relation issued between the natural frequency and the adhesive thickness parameter for high modes, no remarkable effect on frequency is observed for this parameter. Plotted in Fig. 12 is the variation of the natural frequency in terms of the increasing modes for each of the values of the adhesive

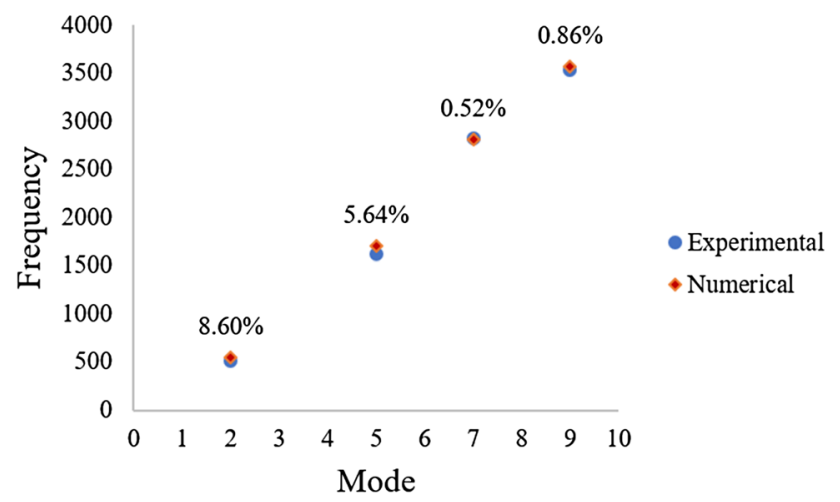

Fig. 8 Numerical-Experimental comparison and relative error percentages

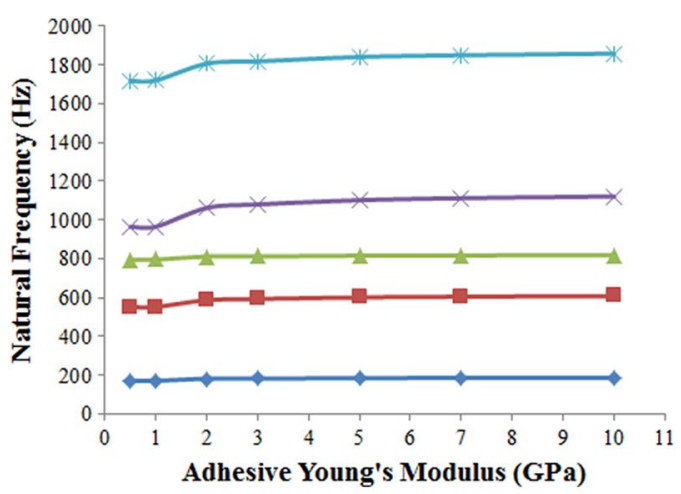

(a) thickness. The curves appear to be strongly consistent which indicates that the interval of frequency variation between thicknesses is effectively mild and negligible.

\subsection{Central adherent thickness}

The free vibration of the structure is simulated with different values of the thickness of the upper and lower plates which are changed from 1 up to $4 \mathrm{~mm}$, the thickness of the central plate is always twice the value of the exterior plates' thickness so its variation is from 2 up to $8 \mathrm{~mm}$. Results of the mode shapes and natural frequencies are graphically presented in Fig. 13. The natural frequency increases almost linearly with the increase of this parameter so one can conclude a direct relation between these variables. Indeed, when adherents thicknesses increase, the stiffness of the structure will increase significantly with a greater order than the mass increase, hence the natural frequencies of the structure rise remarkably. The increase between two consecutive proportional variable values is marked by barely the same percentage for all modes excepting one value of the thickness, differing from one mode to another, where a curvature appears. When changing the thickness from 2 to $3 \mathrm{~mm}$, this percentage is equal to approximately $45 \%$, then becomes equal to $30 \%$ when passing to $4 \mathrm{~mm}$, then for the consecutive jumps in thickness to $5,6,7$ and $8 \mathrm{~mm}$ are respectively $21 \%, 16 \%, 14.5 \%$, and finally $12 \%$. This means that for relatively high values,

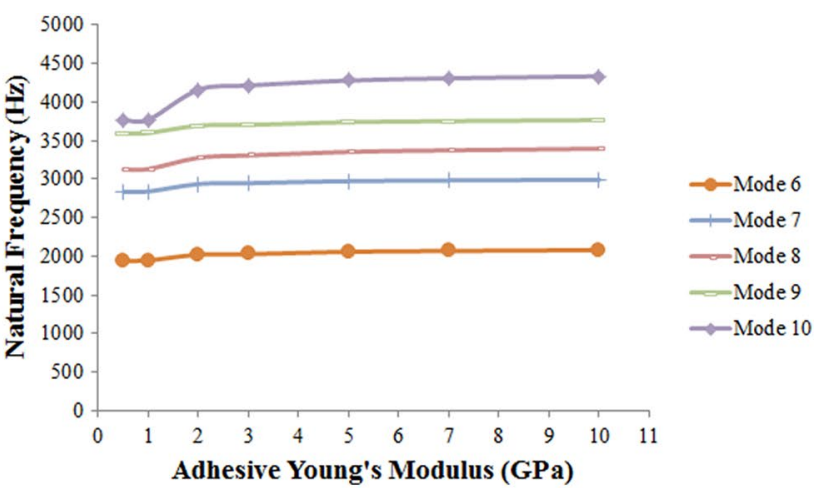

(b)

Fig. 9 Graphical representation of the frequencies resulting from variation of the adhesive elasticity of the reference model a for modes $1-5$ b for modes 6-10 


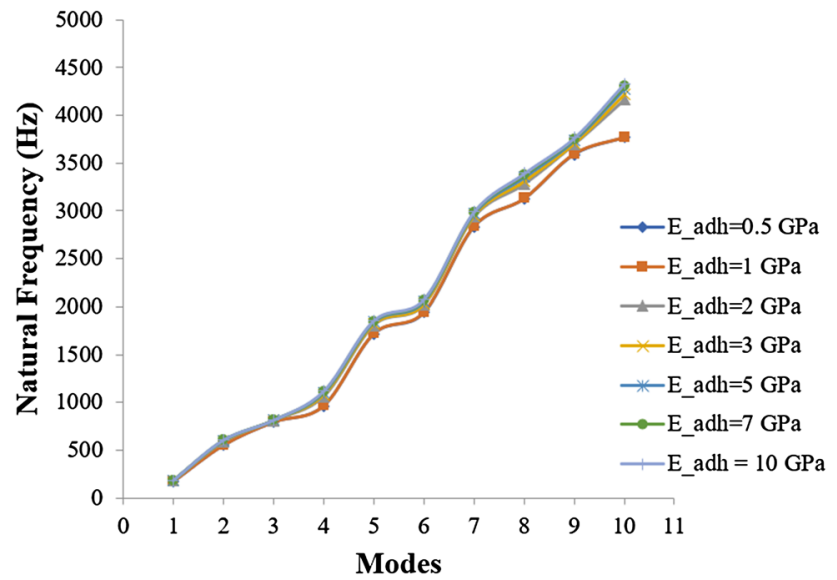

Fig. 10 Variation of natural frequency as function of the first ten modes for the values of the adhesive Young's modulus

this parameter influences less the natural frequency of the assembled parts. Figure 14 represents the variation of the natural frequency as function of the increasing modes from 1 to 10 corresponding to the variable thickness of the central plate. Widely dispersed, the curves depict the large range of frequency covered by the variation of this parameter.

\subsection{Overlap length}

The fourth and last parameter in this study is the overlap length and the variation adopted is from 1 up to $8 \mathrm{~cm}$. Results of the mode shapes and natural frequencies are graphically presented in Fig. 15. It was necessary to go

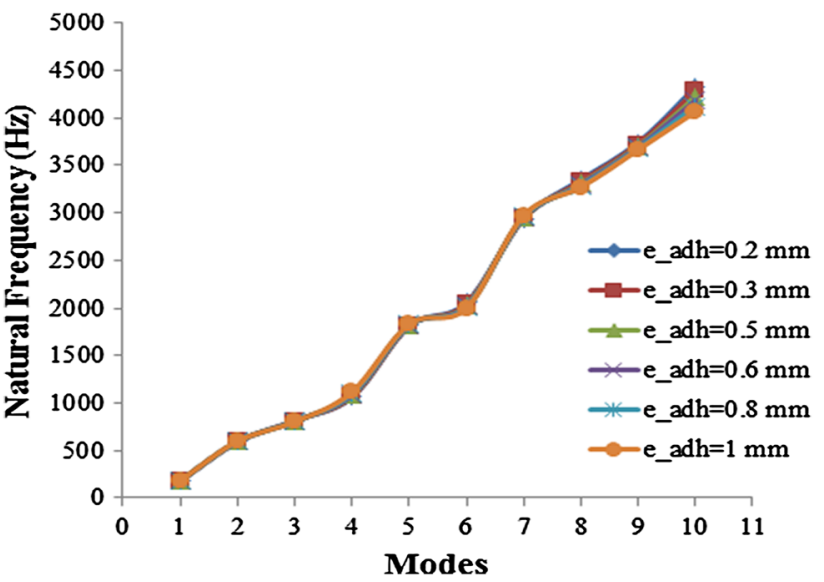

Fig. 12 Variation of natural frequency as function of the first ten modes for the values of the adhesive thickness

beyond the practical values of this parameter to some theoretical values since the overlap ratio represents an important parameter towards determining the overall stiffness and hence it has a strong effect on natural frequency; as the graph shows, there is a direct influence of this parameter. For mode 1 the increase in frequency, from $1 \mathrm{~cm}$ to $8 \mathrm{~cm}$ length, is around 2.86 times $(286 \%)$ its value. The greatest leap in frequency is for the last variation from the ratio 0.6 to 0.8 of average $50 \%$. For an increase in overlap, the free length of the plate is shortened; thus the structure's stiffness increases and leads to an increase in natural frequency. Increase in overlap length, from 10 to $80 \%$ of the structure length is considered high; for a moderate value of the overlap ratio of 0.5 , the natural

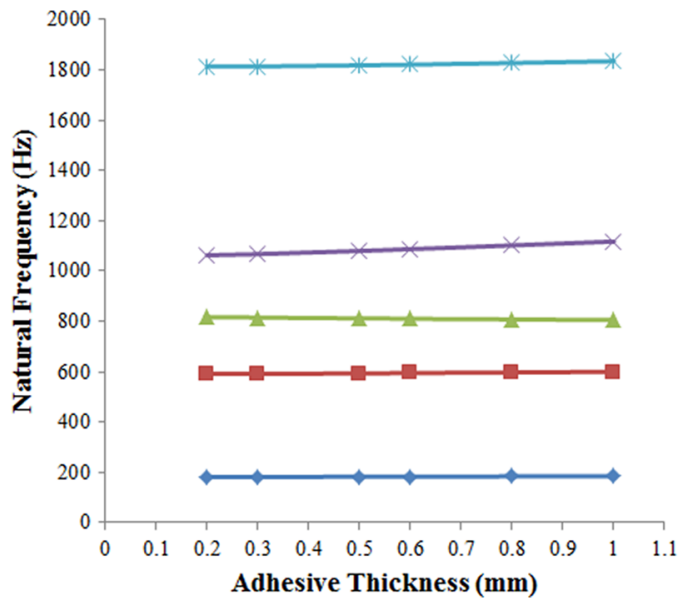

(a)
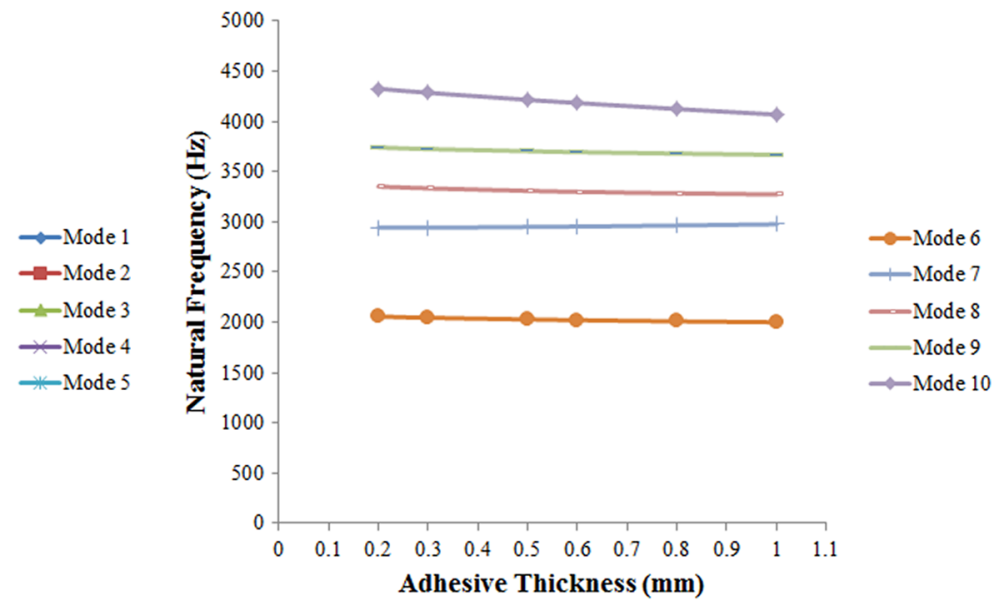

(b)

Fig. 11 Graphical representation of frequencies resulting from variation of the adhesive thickness of the reference model a for modes $1-5 \mathbf{b}$ for modes 6-10 


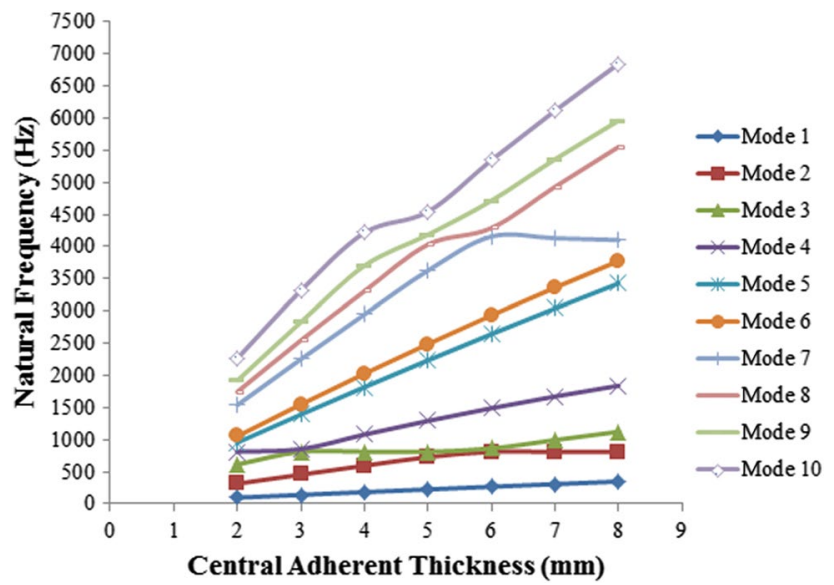

Fig. 13 Graphical representation of the first ten modes resulting from variation of the central plate's thickness of the reference model

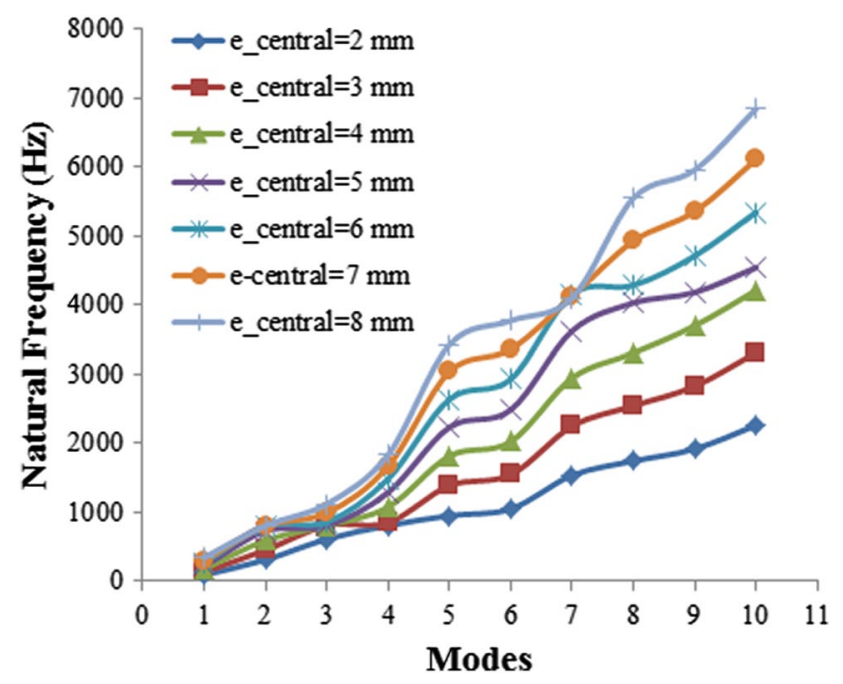

Fig. 14 Variation of natural frequency as function of the first ten modes for each value of the central adherent thickness

frequency increases around $40 \%$ its value for the reference model vibration (with overlap ratio 0.3 ), which is a significant increase. In Fig. 16, where the natural frequency is function of the modes, there is a disparity between isocurves of each overlap length. The observed phenomenon is a proof that the increase in frequency between each overlap length is largely great; generally, the critical role of the overlap ratio in increasing the natural frequency is properly identified.

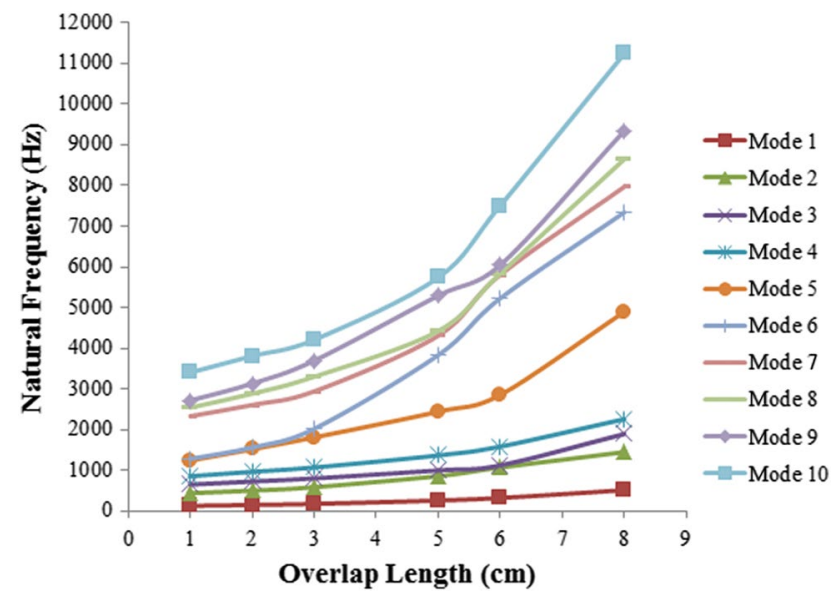

Fig. 15 Graphical representation of the first ten modes resulting from variation of the overlap length of the reference model

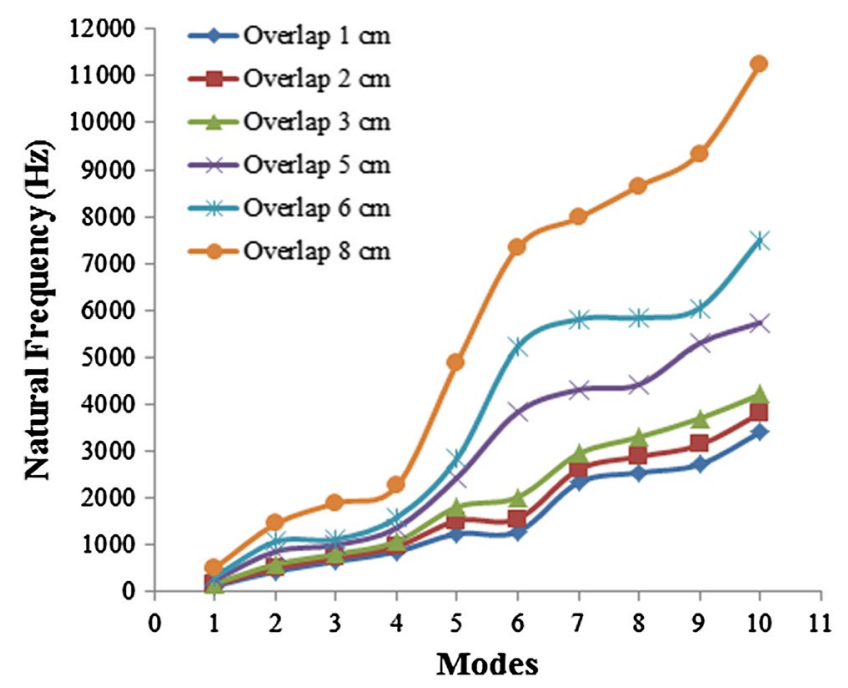

Fig. 16 Variation of natural frequency as function of the first ten modes for each value of the overlap length

\section{Unified parameter}

After examining the influence of each of the previous parameters separately on the natural frequencies of the first ten modes, it is worth to define a unified parameter $\lambda$ involving all those parameters and to investigate the evolution of the natural frequencies of each mode in terms of this parameter. Later, analytical expressions of the natural frequencies of the first ten modes could be established and valid just in the studied margin of the above parameters.

Since the natural frequencies were increasing with the adhesive Young's modulus $\mathrm{E}$, adherent thickness $t_{c}$ and overlap length $a$, and decreasing with the adhesive 

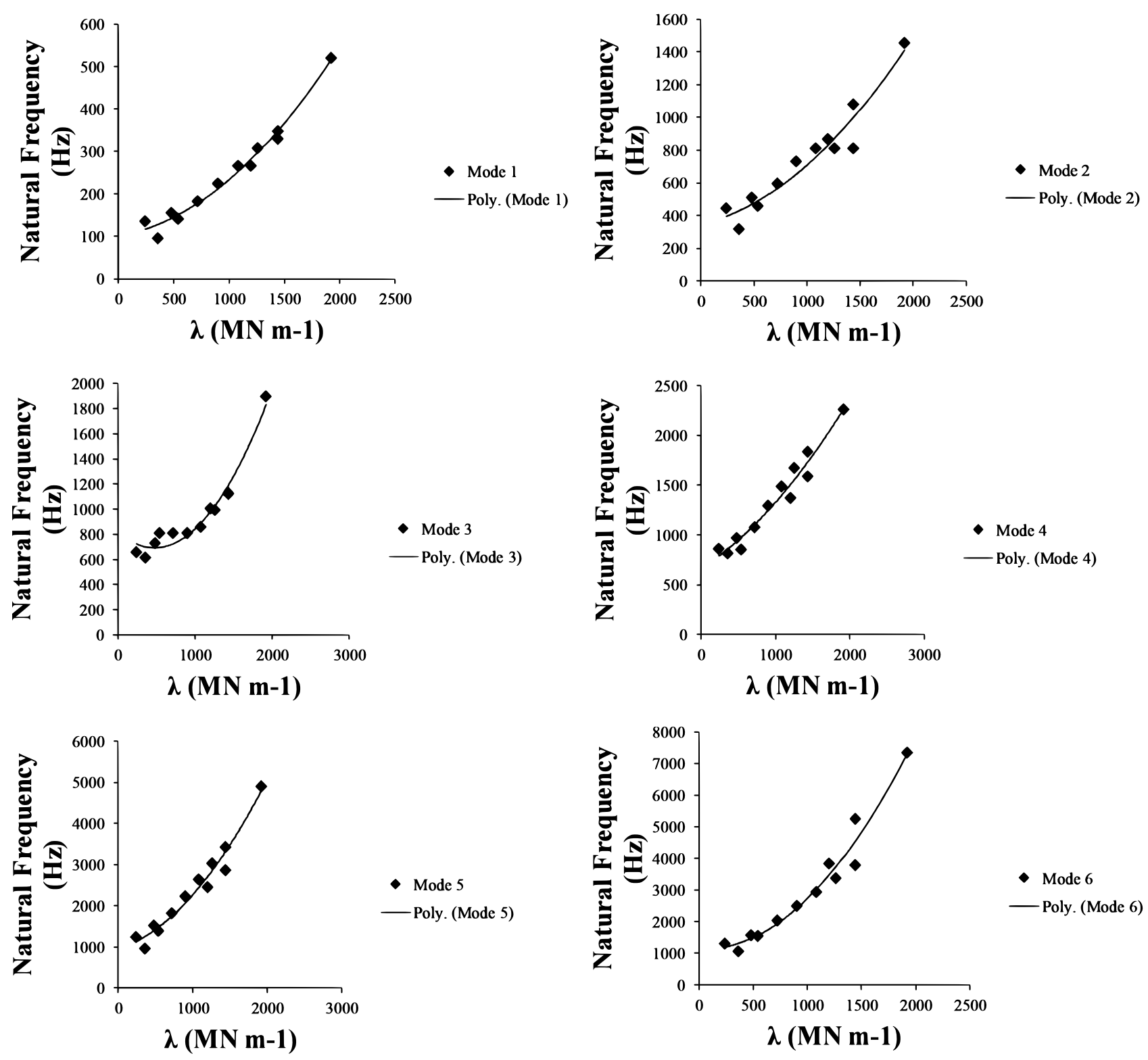

Fig. $17 \omega$ in terms of parameter $\lambda$ with trend-lines for modes $1-10$

thickness $t_{a}$, one may define the unified parameter according to the equation:

$\lambda=\frac{E \cdot a \cdot t_{c}}{t_{a}}$

where $\mathrm{E}$ is expressed in $\mathrm{MPa}$, a in $\mathrm{m}, t_{c}$ and $t_{a}$ in $\mathrm{mm}$.

Moreover, it was shown earlier that the effects of $E$ and ta on the natural frequencies were quite slight, hence their values were set to those of the reference model (Tables 1 and 2). On the other hand, the values of parameters a and $t_{c}$ in Table 5 will be applied value by value (one is set as a reference and the other will be varied) to calculate a group of values for $\lambda$. Knowing the

corresponding values of the natural frequencies related to different modes, one may plot graphs: frequency vs $\lambda$ for each mode alone, then drawing the closest fitting line representing the evolution with a corresponding analytical equation. Graphs of Fig. 17 show the evolution of the frequencies in terms of the unified parameter. One may remark that the global shape of the evolution is quite similar for all modes.

The parabolic form with the analytical expression: $\omega=\alpha \lambda^{2}+\beta \lambda+\gamma$ models the trend lines of the previous curves, where $\alpha, \beta$ and $\gamma$ are set for each mode as presented in Table 7.

Indeed, one may mention many comments on this latter study. First, by observing the expression of the 

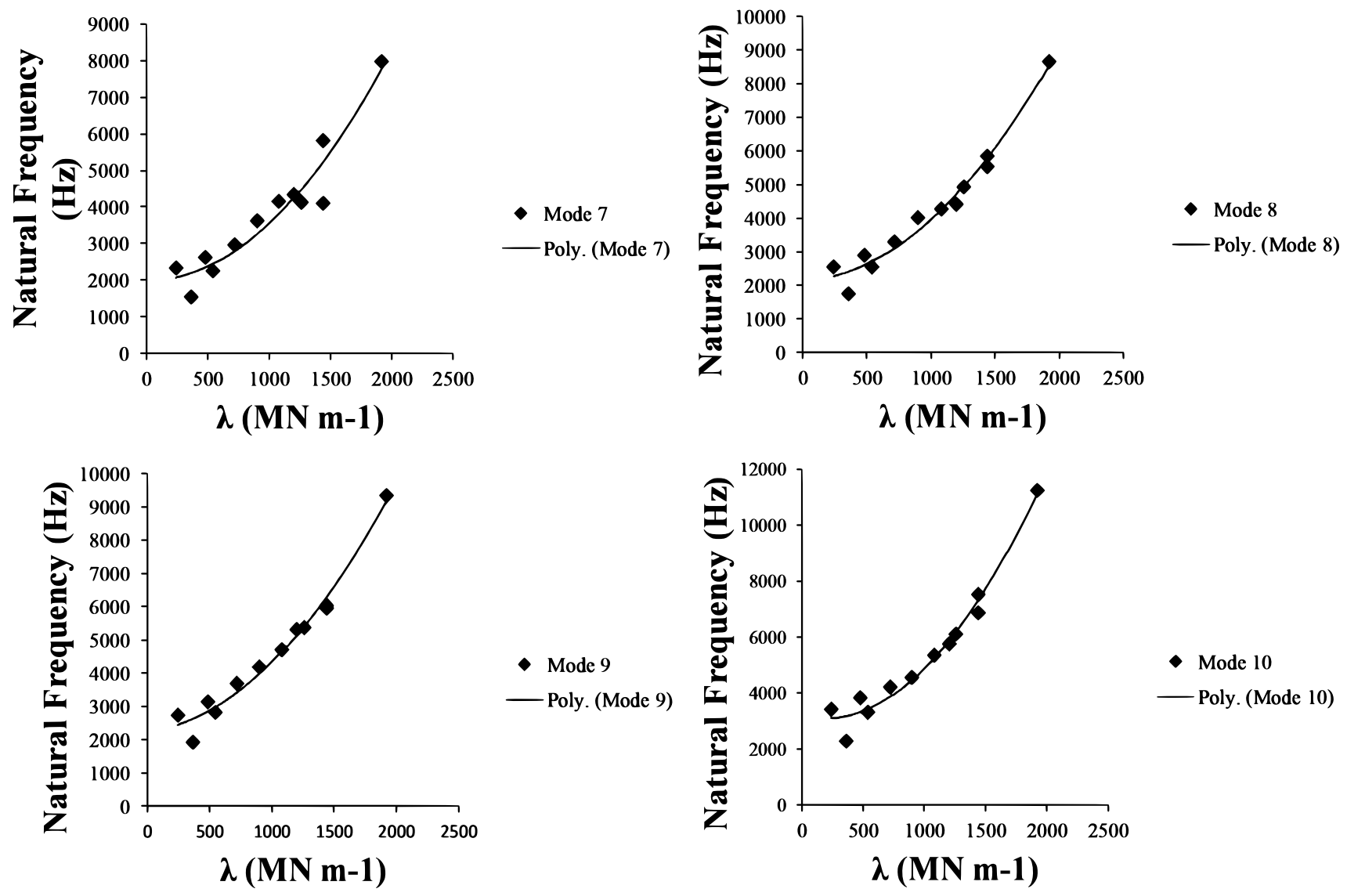

Fig. 17 (continued)

Table 7 Coefficients of the analytical expressions of parabolas corresponding to parameter $\lambda$ for the first ten modes

\begin{tabular}{llcl}
\hline Modes & Coefficient $\alpha$ & Coefficient $\beta$ & Coefficient $\gamma$ \\
\hline Mode 1 & 9E-0.5 & 0.0427 & 101.3 \\
Mode 2 & 0.0002 & 0.1524 & 346.64 \\
Mode 3 & 0.0005 & -0.5168 & 815.28 \\
Mode 4 & 0.0002 & 0.4756 & 663.42 \\
Mode 5 & 0.0007 & 0.5729 & 949.99 \\
Mode 6 & 0.0018 & -0.1532 & 1134.9 \\
Mode 7 & 0.0016 & -0.0046 & 1985.2 \\
Mode 8 & 0.0016 & 0.1694 & 2136 \\
Mode 9 & 0.0016 & 0.4461 & 2250 \\
Mode 10 & 0.0026 & -0.9128 & 3157.1 \\
\hline
\end{tabular}

unified parameter with the corresponding units of each quantity, one can say that the unit of $\lambda$ is $M N \mathrm{~m}-1$ which reflects a stiffness. All graphs of Fig. 17 show a significant increase of the natural frequencies with this parameter, which is in line with the physical aspect of the stiffness influence on the natural frequencies.
Moreover, it should be noticed that the established analytical equations are valid for the discussed range of $\lambda$ and thus for the studied ranges of the overlap length and the adherent thickness. Since the influence of the adhesive Young's modulus and thickness is too slight, one may change their values in a restraint margin without affecting significantly the values of the frequencies.

In addition, the above-established equations, allow designing the geometry of a DLJ structure for the desired frequency, by varying either the overlap length or the adherent thickness or both, depending on the case of study. A compromise could be applied since high overlap lengths increase indeed the natural frequency. But their negative effect is that high-stress concentration will appear in the neighborhood of the adhesive layer, while on the other hand, increasing the adherent thickness will lead to an increase in natural frequency and simultaneously, a more homogeneous stress field in the adhesive layer, however the resulting increase in mass and cost of the structure will play a role in the design. 


\section{Conclusion}

A parametric study of a double-lap bonded joint structure was carried out to investigate the effect of many parameters on the natural frequencies and mode shapes of the first ten modes. Firstly, an experimental test was conducted for the same DLJ structure and was validated numerically for the model. Then, four parameters were varied: adhesive Young's modulus, adhesive thickness, adherent thickness, and overlap length.

A unified parameter is elaborated to evaluate analytically approximate values of the natural frequencies for the first ten modes. This unified parameter could be useful for design purposes. In this phase and before manufacturing, modifications can be brought to the structure based on the frequencies according to the targeted application of a similar assembly.

\section{Compliance with ethical standards}

Conflict of interest On behalf of all authors, the corresponding author states that there is no conflict of interest.

\section{References}

1. Saito H, Taini H (1984) Vibrations of bonded beams with single lap adhesive joint. J Sound Vib 92(2):299-309

2. Khalil AA, Kagho AN (1991) Non-destructive testing of adhesively bonded joints using vibrational analysis. Int J Adhes Adhes 11(2):121-127

3. He S, Rao MD (1992) Vibration analysis of adhesively bonded lap joints, part I: theory. J Sound Vib 152(3):405-416

4. Rao MD, He S (1992) Vibration analysis of adhesively bonded lap joints, part II: numerical solution. J Sound Vib 152(3):417-425

5. Rao MD, Zhou H (1994) Vibration and damping of a bonded tubular lap joint. J Sound Vib 178(5):577-590

6. Ko TC, Lin CC, Chou RC (1995) Vibration of bonded laminated lap-joint plates using adhesive interface elements. J Sound Vib 184(4):567-583

7. Lin CC, Ko TC (1997) Free vibration of bonded plates. Comput Struct 64(1-4):441-452

8. Yeh MK, You YL (1995) Vibration of laminated plates with adhesive joints. Compos Eng 5(8):983-993

9. He X, Oyadiji SO (2001) Influence of the adhesive characteristics on the transverse free vibration of single lap-jointed cantilevered beams. J Mater Process Technol 119:366-373

10. Vaziri A, Hamidzadeh HR, Nayeb-Hashemi H (2001) Dynamic response of adhesively bonded single-lap joints with a void subjected to harmonic peeling load. Proc Inst Mech Eng Part $\mathrm{K}$ J Multi-body Dyn 215(4):199-206

11. Vaziri A, Nayeb-Hashemi $\mathrm{H}$ (2002) Dynamic response of tubular joints with an annular void subjected to a harmonic axial load. Int J Adhes Adhes 22:367-373
12. Vaziri A, Nayeb-Hashemi H (2006) Dynamic response of a repaired composite beam with an adhesively bonded patch under a harmonic peeling load. Int J Adhes Adhes 26:314-324

13. Gunes R, Apalak MK, Yildirim M (2007) The free vibration analysis and optimal design of an adhesively functionally graded single lap joint. Int J Mech Sci 49:479-499

14. Gunes R, Apalak MK, Yildirim M, Ozkes I (2010) Free vibration analysis of adhesively bonded single lap joints with wide and narrow functionally graded plates. Compos Struct 92:1-17

15. He X (2014) Finite element analysis of torsional free vibration of adhesively bonded single-lap joints. Int J Adhes Adhes 48:59-66

16. Garcia-Baruetabeña J, Cortés F (2014) Experimental analysis of the vibrational response of an adhesively bonded beam. Measurement 55:238-245

17. Du Y, Shi L (2014) Effect of vibration fatigue on modal properties of single lap adhesive joints. Int J Adhes Adhes 53:72-79

18. Samaratunga D, Jha R, Gopalakrishnan S (2015) Wave propagation analysis in adhesively bonded composite joints using the wavelet spectral finite element method. Compos Struct 122:271-283

19. Challita G, Othman R (2012) Analytical model of the double-lap bonded joints response to harmonic loads. Eur J Mech A/Solids 34:149-158

20. Zeaiter A, Challita G, Khalil K (2016) Influence of substrates materials on vibration modes of a double-lap bonded joint. In: Proceedings of the 11th HSTAM international congress on mechanics, 27-30 May, Athens

21. Challita G, Othman R (2010) Finite-element analysis of SHPB tests on double-lap adhesive joints. Int J Adhes Adhes 30:236-244

22. Hazimeh R, Challita G, Khalil K, Othman O (2015) Finite element analysis of adhesively bonded composite joints subjected to impact loadings. Int J Adhes Adhes 53:24-31

23. Saleh P, Challita G, Hazimeh R, Khalil K (2015) Influence of composite adherents properties on the dynamic behaviour of double lap bonded joint. Int J Chem Nucl Mater Met Eng 9(4):410-416

24. Saleh P, Challita G, Hazimeh R, Khalil K (2015) Stress homogeneity in adhesive layer of composite double lap joint under dynamic shear loading. Compos Theory Pract 15(2):101-106

25. Saleh P, Challita G, Khalil K (2015) Stress concentration coefficient in a composite double lap adhesively bonded joint. Int J Adhes Adhes 63:102-107

26. Challita G, Othman R, Casari P, Khalil K (2011) Experimental investigation of the shear dynamic behaviour of double-lap adhesively bonded joints on a wide range of strain rates. Int J Adhes Adhes 31:146-153

27. Hazimeh R, Challita G, Khalil K, Othman R (2015) Experimental investigation of the influence of substrates fibers' orientations on the impact response of composite double-lap joints. Compos Struct 134:82-89

28. ASTM E1876, (2015) Standard test method for dynamic Young's modulus, shear modulus, and Poisson's ratio by impulse excitation of vibration. ASTM International, West Conshohocken

29. Slim MF, Alhussein A, Billard A, Sanchette F, François M (2016) On the determination of Young's modulus of thin film with impulse excitation technique. J Mater Res 32:497-511

30. Salloum E (2016) Modal analysis of adhesively composite double-lap joints. Masters' thesis, Lebanese University, Faculty of Engineering

Publisher's Note Springer Nature remains neutral with regard to jurisdictional claims in published maps and institutional affiliations. 